\title{
Ability of Fungi, Isolated from Nsukka Peppers and Garden-Egg Plant Rhizospheres, to Solubilize Phosphate and Tolerate Cadmium
}

\author{
C. E. Onyia', C. U. Anyawu'2, M. N. Ikegbunam ${ }^{3 *}$ \\ ${ }^{1}$ Biotechnology Centre, University of Nigeria, Nsukka, Nigeria \\ ${ }^{2}$ Department of Microbiology, University of Nigeria, Nsukka, Nigeria \\ ${ }^{3}$ Department of Pharmaceutical Microbiology and Biotechnology, Nnamdi Azikiwe University, Awka, Nigeria \\ Email: ${ }^{*}$ mn.ikegbunam@unizik.edu.ng
}

Received 28 May 2015; accepted 5 July 2015; published 8 July 2015

Copyright (C) 2015 by authors and Scientific Research Publishing Inc. This work is licensed under the Creative Commons Attribution International License (CC BY). http://creativecommons.org/licenses/by/4.0/ (c) (i) Open Access

\section{Abstract}

Fungi were isolated from the rhizosphere of pepper and garden-egg plants, with the aim of solubilizing the insoluble phosphate, identifying the most potent isolate from each rhizosphere and testing their tolerance to cadmium metal. The fungi isolates were obtained from the rhizosphere of pepper and garden-egg plants, using PVK agar and NBRIP-BPB broth culture to determine the quantity of phosphate solubilized. From the spectrophotometric readings, isolates GF1 (Penicillium spp) and PF7 (Aspergillus niger) were identified as most potent isolates. Various concentrations of cadmium $(100,50,10$ and $1 \mu \mathrm{g} / \mathrm{ml})$ were added to the broth containing different isolates for tolerance determination and a control group for different isolates were also obtained. At fourday interval, a quantity of phosphates solubilized at different concentrations of cadmium and control were recorded. The quantity solubilized in 100, 50, 10 and $1 \mu \mathrm{g} / \mathrm{ml}$ treatment groups increased progressively from Day 4 to Day 12 in both isolates, with a sharp increase observed in isolate GF1. The tolerance of GF1 to cadmium showed that there was no significant difference (P < 0.05) in quantity solubilized in the control group when compared with Day 8 and Day 12 of 1 $\mu \mathrm{g} / \mathrm{ml}$ concentration of cadmium metal, except at Day 4 which may be as a result of acclimatization. The quantity solubilized for PF7 at control when compared with $1,10,50$ and $100 \mu \mathrm{g} / \mathrm{ml} \mathrm{dif-}$ fered significantly although there were higher quantity of phosphates solubilized when compared with GF1 and other results obtained from most published works. Our results suggested that these two isolates could be used for phosphate solubilization in cadmium metal environment though GF1 tolerates more than PF7, and could be employed for bioremediation of cadmium heavy metals.

\footnotetext{
${ }^{*}$ Corresponding author.
} 


\section{Keywords}

\section{Fungi, Pepper, Garden Egg, Phoshate and Cadmium}

\section{Introduction}

Apart from nitrogen, phosphorus is one major nutrient required for healthy growth of plants [1], but is highly immobile making phosphorus inaccessible by plants. According to Khan et al. [2], root development, stem strength development, flower and seed formation and crop maturity are some the attributes associated with phosphorus nutrition. Phosphorus deficiency is one of the major constraints for crop production; the availability of phosphorus in the soil is somewhat limited, notwithstanding the large amounts of soluble form of phosphate fertilizers that are applied to attain maximum crop production. However, the applied soluble forms of phosphate fertilizers are easily precipitated into insoluble forms such as Tricalcium phosphate $\left[\mathrm{Ca}_{3}\left(\mathrm{PO}_{4}\right)_{2}\right]$, Iron phosphate $\left(\mathrm{FePO}_{4}\right)$ and Aluminium phosphate $\left(\mathrm{AlPO}_{4}\right)$ ([3]; Barroso et al., 2006). It has been found that despite phosphate fertilizer wide distribution in nature, phosphate is deficient in most soils and its content is about $0.05 \%$ of which only $0.1 \%$ is needed for plant [4]. Though some beneficial microorganisms (phosphate solubilizing microorganism) in the soil are found to convert insoluble-phosphate into soluble form by the process of acidification, chelation and exchange reactions [5], thereby reducing the insoluble phosphate. Today, soil pollution by heavy metal has become one of the serious issues of concern amongst all environmental crises [6]. Heavy metals that pollute the environment exist in soil as free metal ions or exchangeable metal ions [7]. They arise in soil by repeated applications of sewage sludge, municipal wastes, animal slurries, activity of mining and smelting industries, impurities in fertilizers and deposition of air pollutants by burning of fossil fuels and various industrial activities [8]. Heavy metals (like Cadmium) persist in soil by having a very slow leaching rate, hence accumulating in soils making microbes vulnerable and unable to solubilize phosphate [9]. In naturally polluted environments, the microbe's response to heavy metals toxicity depends on the concentration and the availability of metals and on the action of factors such as the type of metal, the nature of medium and microbial species [10] but some fungi and yeast biomass are known to tolerate heavy metals at very low concentration [11] [12]. The high concentration of microorganisms within the rhizosphere may be as a result of compounds exuded by plant roots, and microorganism feeds on these compounds. This forms an important and intensive interaction that takes place among plants, soil and microorganisms [13] resulting in an increased microbial biomass within the rhizosphere. The objective of our study was to isolate and characterize phosphate solubilizing rhizofungi that are able to solubilize insoluble phosphates efficiently under environmental stress (i.e. presence of cadmium metal).

\section{Materials and Methods}

\subsection{Soil Sample Collection}

Samples were collected from rhizospheres of pepper plants and garden-egg plants, at University of Nigeria, Nsukka agric farm. The soil samples were taken within the rhizospheric circumference of $1-10 \mathrm{~cm}$ radius by 5 $10 \mathrm{~cm}$ depths. The soil samples were collected with a sterile container and were sent to laboratory immediately.

\subsection{Isolation of Indigenous (Autochthonous) Rhizospheric Fungi}

From each soil sample, $10 \mathrm{~g}$ were transferred to $250 \mathrm{ml}$ Erlenmeyer flask each containing $90 \mathrm{ml}$ of sterile distilled water. The flasks were shaken for about 20 minutes and $1 \mathrm{ml}$ of the mixture were transferred to $9 \mathrm{ml}$ of distilled water in test tube and serially diluted. The appropriate dilution is plated out using a pour plate method, where $0.1 \mathrm{ml}$ aliquots of the dilutions are plated on potato dextrose agar (PDA) medium. The spraying method were also used where soil samples were sprinkled directly on some plates and incubated.

\subsection{Isolation of Phosphate Solubilizers Using PVK Agar}

Each fungal isolate were aseptically transferred onto Pikovskaya [14] medium (PVK) supplemented with bromo-phenol-blue (BPB) and tri-calcium phosphate (TCP) using point inoculation and incubated at $28^{\circ} \mathrm{C} \pm 2^{\circ} \mathrm{C}$ for 7 days. The solubilisations of phosphate were observed as a zone of clearance with a diameter that was meas- 
ured in millimetres. The phosphate solubilization ability of the fungi was analyzed by determining the phosphate solubilization efficiency $(\mathrm{E})$ of each isolate. [E = solubilization diameter/growth diameter $\times 100$ ] (Nguyen, et al., 1992) sited by Qurban [15]. After confirming the phosphate solubilizing ability on solid medium, the phosphate solubilization were also carried out using National Botanical Research Institute's Phosphate-Bromo Phenol Blue (NBRIP-BPB) broth.

\subsection{Confirmation of Phosphate Solubilizers Using NBRIP-BPB Broth}

$12 \mathrm{~mm}$ cork bowered inoculums sizes of a 5 day-culture grown in the PDA were used as the inoculums size. The phosphate solubilization activity of each of the isolates were determined by growing the isolates in NBRIP medium containing a pH indicator (Bromophenol Blue) for 12 day (taken reading at 4 day interval) at $29^{\circ} \mathrm{C} \pm 2^{\circ} \mathrm{C}$. At the end of the incubation period, spectrophotometric readings were taken at OD600 and the final values were subtracted from the (control) initial values [16].

\subsection{Effect of Cadmium Heavy Metal on Fugal Phosphate Solubilization}

To find out the effect of heavy metal (Cadmium) in the phosphate solubilizing activity of GF1 and PF7 fungal species, NBRIP-BPB broth was prepared with varying concentrations of cadmium $(0,1,10,50,100 \mu \mathrm{g} / \mathrm{ml})$. The zero (0) cadmium concentration is the control to check the effect of phosphate solubilization at varying concentration.

\subsection{Identification of Potent Fungi}

The most potent fungi isolate from each of the rhizosphere were characterized and identified on the basis of morphological and microscopic features using lactophenolcotton-blue. Among the characteristics used were colonial characteristics such as surface appearance, texture and colour of the colonies. In addition, microscopy revealed vegetative mycelium including presence or absence of cross-walls, diameter of hyphae. Appropriate references were then made using mycological identification keys and taxonomic description [17].

\subsection{Statistical Analysis}

All experiments were carried out in triplicates and mean data were subjected to Analysis of Variance (ANOVA) using GenStat package.

\section{Results and Discussion}

Microbial solubilization of phosphate materials has been studied as a means of releasing phosphate contents from cationic metal ore, and as alternative process for producing soluble phosphate [18]. The most intensively studied aspects of microbial phosphate solubilization have been the provision of phosphate for plant up-takes by the solubilization of insoluble phosphates in rhizosphere environment [19], though some environmental factors such as temperature, $\mathrm{pH}$ and presence of some heavy metals affects microbial phosphate solubilization. But in our study, fourteen (14) fungal species were isolated from University of Nigeria, Nsukka agricultural soil and were tested for their phosphate solubilization activity. But today, heavy metal pollution has become one of the serious issues of concern amongst all environmental crises. Heavy metals are one of the major sources of environmental pollutants and exist in soil as free metal ions [6]. Aspergillus niger (PF7) and Penicillum spp (GF1) were found as an efficient (potent) organisms that are able to release high amounts of phosphate from insoluble phosphate ores in presence of cadmium metal. These isolates PF7 and GF1 were found to solubilize tricalcium phosphate (TCP) in cadmium metal environment at ambient (optimum) $\mathrm{pH}$ and temperature ranges of $\mathrm{pH} 7$ and $28^{\circ} \mathrm{C} \pm 2^{\circ} \mathrm{C}$ respectively, though presence of cadmium metal slightly affects quantity solubilized. But for PF7 and GF1 fungi isolates there were significant difference $(\mathrm{P}<0.05)$ in quantity solubilized in the control group when compared with all tested concentration of cadmium, except at Day 8 and Day 12 of $1 \mu \mathrm{g} / \mathrm{ml}$ of GF1. This indicates that though PF7 isolate solubilizes more phosphates than GF1, but GF1 tolerates more cadmium and this supports the work done by Ezzouhri et al., [9] which stated that Cadmium (Cd) at a concentration of $1 \mathrm{mM}$ showed the strongest inhibition towards isolates from the genera Aspergillus, Fusarium, Alternaria and Geotrichum but only Penicillium isolates were able to grow at such cadmium concentration. From the preliminary test, 
reported by Mergeay et al. [20] and Kermasha et al. [21], heavy metal-resistant filamentous fungi were selected and the minimal inhibitory concentration (MIC) to $\mathrm{Cr}, \mathrm{Pb}, \mathrm{Cu}$ and $\mathrm{Zn}$ was determined. No determinations were made for cadmium since the majority of the tested fungi were unable to grow in the presence of the cadmium metal. All these reports indicated that cadmium metal is toxic to microorganisms and serves as a hindrance to fungi phosphate solubilizers, but in our research work we were able to isolate fungi that can grow at such high concentration of toxic cadmium environment.

\section{Conclusions}

Our findings indicate that fungal populations isolated from rhizosphere of pepper and garden-egg have the ability to solubilize insoluble phosphate and resist higher concentrations of toxic cadmium metal. A comparative level of cadmium metal resistance was also shown that filamentous fungi originating from garden-egg rhizosphere were more tolerant to cadmium environment. The tolerance and the resistance of the isolates depended much more on the fungus tested and on the sites of its isolation. This variation may be explained by the development of tolerance or adaptation of the fungi to heavy metals. Aspergillus and Penicillium isolates were the most resistant to cadmium metal tested, with Penicillium having an edge over Aspergillus. This may make them promising candidates for further investigations regarding their ability to remove metals form contaminated environments.

\section{Figures}

Out of eight (8) fungi isolated from garden-egg rhizosphere, five were able to solubilize insoluble phosphate as were shown in Figure 1(a), while GF12, GF15 and GF16 were unable to solubilize, though there are growths. Figure 1(b) showed that all the eight isolates were able to solubilize insoluble phosphate in broth culture. On

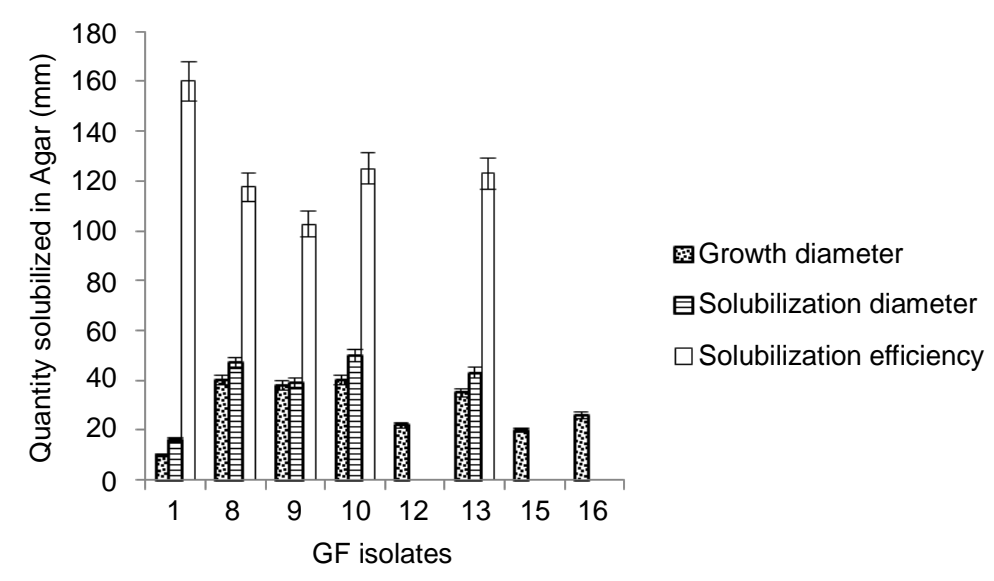

(a)

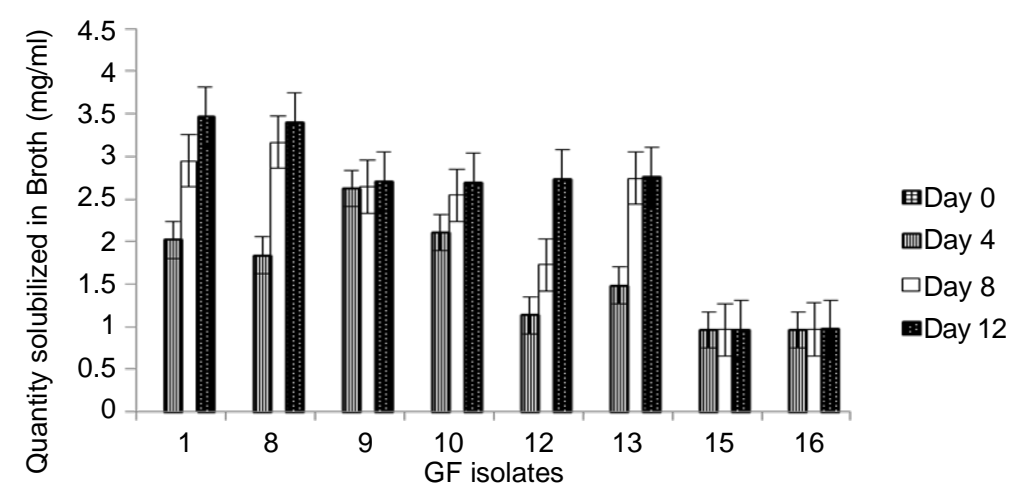

(b)

Figure 1. (a) Phosphate solubilization for garden-egg fungal isolates using agar technique; (b) Phosphate solubilization for garden-egg fungal isolates using broth technique. 
comparing the two techniques, it was observed that isolate GF1 showed highest solubilization in both technique and were selected as the most efficient isolate for GF isolates.

Fungi isolate PF2, PF3, PF4, PF5, PF6 \& PF7 were isolated from the rhizosphere of pepper. Figure 2(a) and Figure 2(b) showed that all the isolates were able to solubilize the insoluble phosphate with isolate PF7 showing the highest solubilization efficiency of 240 and broth solubilization of $4.2 \mathrm{mg} / \mathrm{ml}$. Isolate PF7 is now selected as the most potent isolate within PF group.

Solubilization performances of the two isolates in varying cadmium environment as was shown in Figure 3(a) and Figure 3(b) indicated that there is no solubilization at Day 0 for both isolates. The obtained results indicated that at GF1, there is no significant difference (P > 0.05) between control (no cadmium metal) and $1 \mu \mathrm{g} / \mathrm{ml}$ concentration of cadmium except at Day 4 of $1 \mu \mathrm{g} / \mathrm{ml}$. The result in Figure 3(a) showed that there are no significant difference ( $\mathrm{P}>0.05$ ) between Day 8 and Day 12 of all the varied concentration, but differed significantly when compared with Day 4.

The PF7 isolate in Figure 3(b) showed that there are significant differences between control and other cadmium varied concentration, significant difference $(\mathrm{P}>0.05)$ between Day 4 and Day 8 but no significant difference between Day 8 and Day 12 of all the various cadmium treatment.

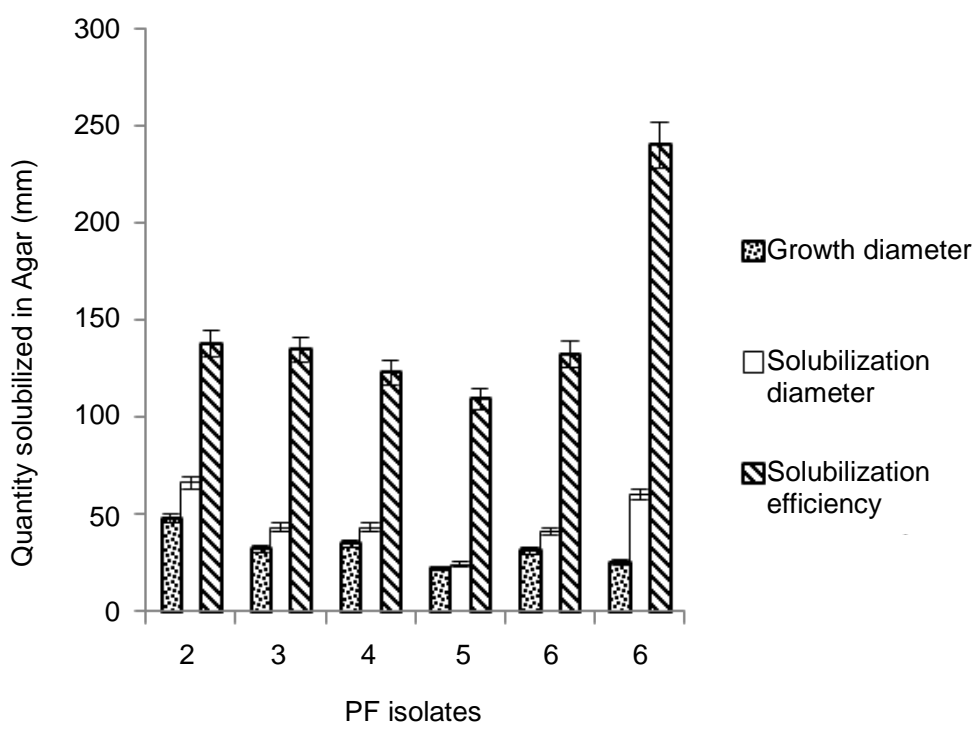

(a)

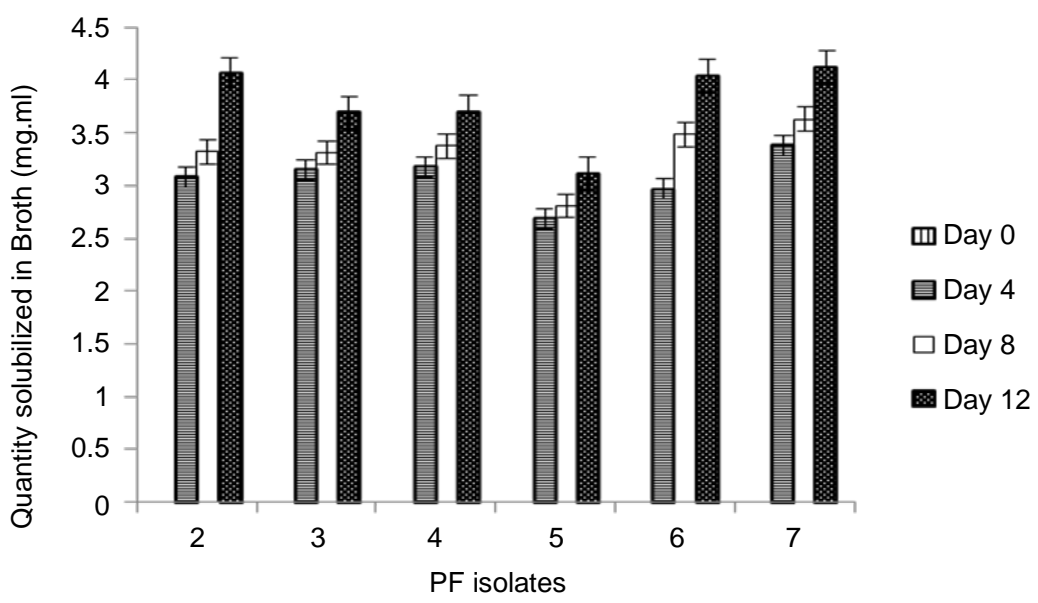

(b)

Figure 2. (a) Phosphate solubilization for pepper fungal isolates using agar technique; (b) Phosphate solubilization for pepper fungal isolates using broth technique. 


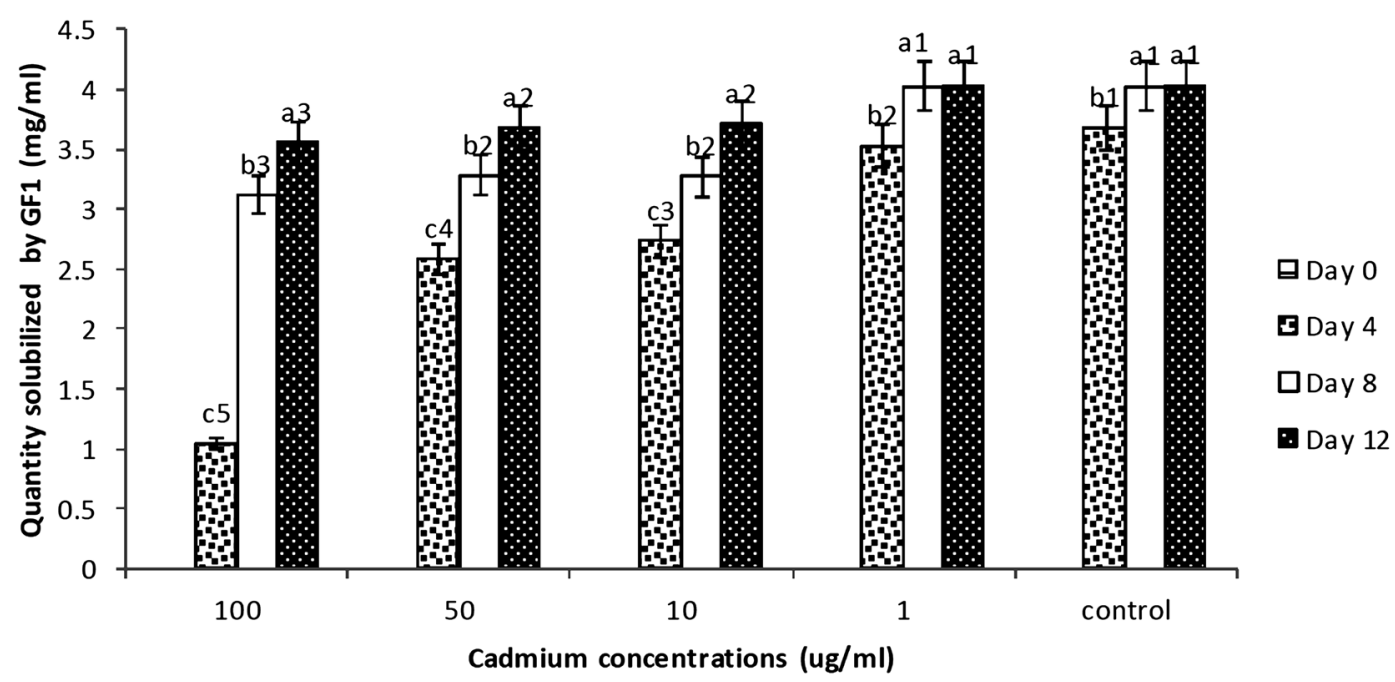

(a)

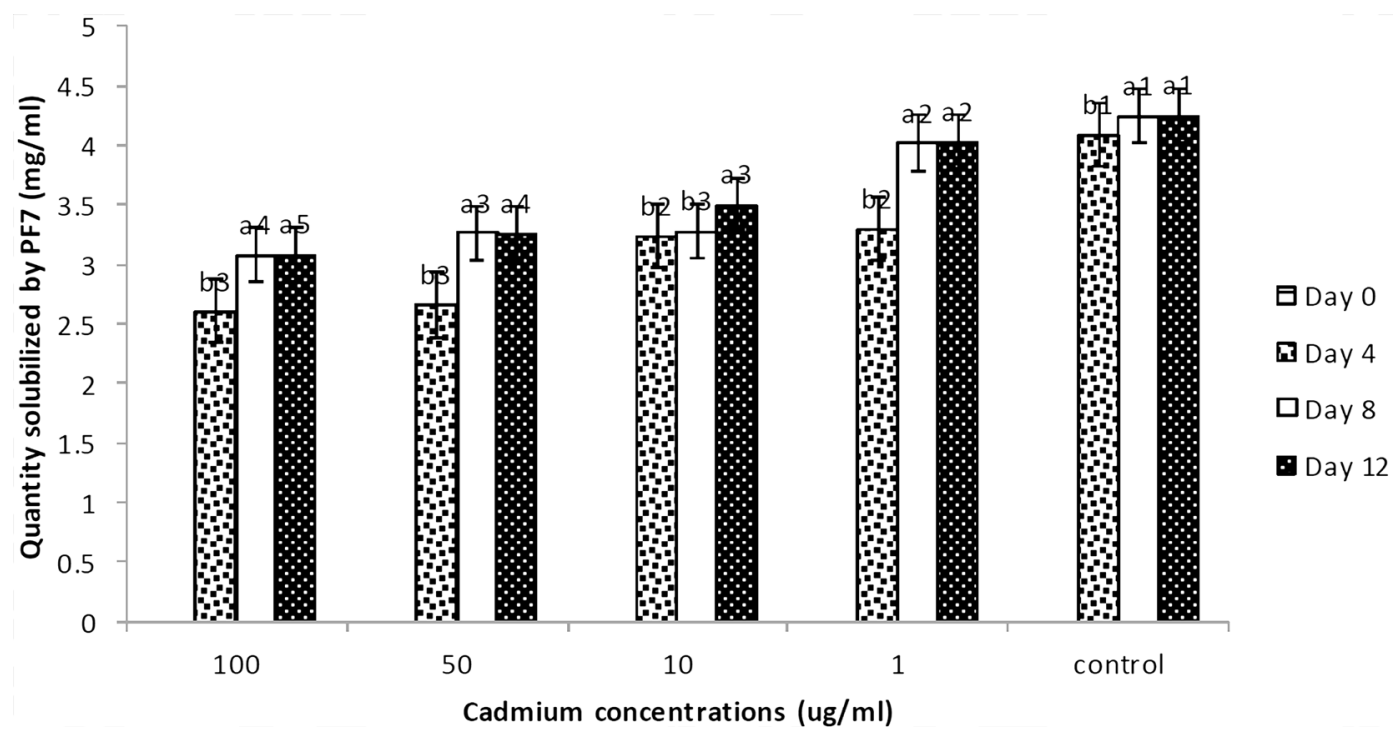

(b)

Figure 3. (a) GF1 solubilization efficacy at varying cadmium concentration. Mean values \pm SE in row with different superscripts number are significantly different $(\mathrm{P}<0.05)$ while same numbers are not significantly different. Superscript letters in each column with the same letter are not significantly different while different letters are significantly different according to GenStat's LSD test $(\mathrm{P}<0.05)$; (b) PF7 solubilization efficacy at varying cadmium concentration. Mean values $\pm \mathrm{SE}$ in row with different superscripts number are significantly different $(\mathrm{P}<0.05)$ while same numbers are not significantly different. Superscript letters in each column with the same letter are not significantly different while different letters are significantly different according to GenStat's LSD test $(\mathrm{P}<0.05)$.

\section{Acknowledgements}

The authors feel grateful to Director of the South East Zonal Biotechnology Centre, University of Nigeria, Nsukka Prof. C. E. A. Okezie for his support.

\section{References}

[1] Akintokun, A.K., Akande, P.O., Popoola, T.O.S. and Babalola, A.O. (2007) Solubilization of Insoluble Phosphate by Organic Acid-Producing Fungi Isolated from Nigerian Soil. International Journal of Soil Science, 2, 301-307. http://dx.doi.org/10.3923/ijss.2007.301.307 
[2] Khan, M.S., Zaidi, A. and Wani, P.A. (2007) Role of Phosphate-Solubilizing Microorganisms in Sustainable Agriculture-A Review. Agronomy for Sustainable Development, 27, 29-43. http://dx.doi.org/10.1051/agro:2006011

[3] Achal, V., Sudhakara, R.M. and Savan, V.V. (2007) Phosphate Solubilization by a Wild Type Strain and UV-Induced Mutants of Aspergillus tubingensis. Journal of Soil Biology and Biochemistry, 39, 695-699. http://dx.doi.org/10.1016/j.soilbio.2006.09.003

[4] Richa, G., Khosla, B. and Reddy, M.S. (2007) Improvement of Maize Plant Growth by Phosphate Solubilizing Fungi in Rock Phosphate Amended Soils. World Journal of Agricultural Sciences, 3, 481-484.

[5] Aadarsh, P., Deepa, V., Murthy, P.B., Deecaramna, M., Sridhar, R. and Dhandapani, P. (2011) Insoluble Phosphate Solubilization by Bacterial Strains Isolated from Rice Rhizosphere Soils from Southern India. International Journal of Soil Science, 6, 134-141. http://dx.doi.org/10.3923/ijss.2011.134.141

[6] Nanda, S. and Abraham, J. (2011) Impact of Heavy Metals on the Rhizosphere Microflora of Jatropha multifida and Their Effective Remediation. African Journal of Biotechnology, 10, 11948-11955.

[7] Leyval, C., Turnau, K. and Haselwandter, K. (1997) Effect of Heavy Metal Pollution on Mycorrhizal Colonization and Function: Physiological, Ecological and Applied Aspects. Mycorrhizal, 7, 139-153. http://dx.doi.org/10.1007/s005720050174

[8] Wang, H., Kimberley, M.O. and Schlegelmilch, M. (2001) Biosolids Derived Nitrogen Mineralization and Transformation in Forest Soils. Journal of Environmental Quality, 32, 1851-1856. http://dx.doi.org/10.2134/jeq2003.1851

[9] Ezzouhri, L., Castro, E., Moya, M., Espinola, F. and Lairini, K. (2009) Heavy Metal Tolerance of Filamentous Fungi Isolated from Polluted Sites in Tangier, Morocco. African Journal of Microbiology Research, 3, 35-48.

[10] Hassen, A., Saidi, N., Cherif, M. and Boudabous, A. (1998) Resistance of Environmental Bacteria to Heavy Metals. Bioresources and Technology, 64, 7-15. http://dx.doi.org/10.1016/S0960-8524(97)00161-2

[11] Gavrilesca, M. (2004) Removal of Heavy Metals from the Environment by Biosorption. Engineering in Life Sciences, 4, 219-232. http://dx.doi.org/10.1002/elsc.200420026

[12] Baldrian, P. (2003) Interactions of Heavy Metals with White-Rot Fungi. Enzyme and Microbiology Technology, 32, 78-91. http://dx.doi.org/10.1016/S0141-0229(02)00245-4

[13] Antoun, H. and Prevost, D. (2006) Ecology of Plant Growth Promoting Rhizobacteria. In: Siddiqui, Z.A., Ed., PGPR: Biocontrol and Biofertilization, Springer, Dordrecht, 1-38. http://dx.doi.org/10.1007/1-4020-4152-7_1

[14] Pikovskaya, R.I. (1948) Mobilization of Phosphorus in Soil Connection with the Vital Activity of Some Microbial Species. Microbiology, 17, 362-370.

[15] Qurban, A.P., Radziah, O., Zaharah, A.R., Sariah, M. and Mohd, R.I. (2012) Isolation and Characterization of Phosphate-Solubilizing Bacteria from Aerobic Rice. African Journal of Biotechnology, 11, 2711-2719.

[16] Nautiyal, C.S. (1999) An Efficient Microbiological Growth Medium for Screening Phosphate Solubilizing Microorganisms. Federation of European Microbiological Societies (FEMS), 170, 265-270. http://dx.doi.org/10.1111/j.1574-6968.1999.tb13383.x

[17] David, E., Stephen, D., Helen, A., Rosemary, H. and Robyn, B. (2007) Descriptions of Medical Fungi. Second Edition, National Library of Australia Cataloguing, Canberra.

[18] Mohamed, A.H., Mohamed, M.G., Omima, A.E. and Asmaa, M.A. (2009) Evaluation and Optimization of Rock Phosphate and Tri-Calcium Phosphate Solubilization by Soil Fungi. Egypt Journal of Experimental Biology, 5, 75-84.

[19] Bolan, N.S., Naidu, R. and Mahimairaja, S. (1995) Influence of Low Molecular Organic Acids on Solubilization of Phosphorus in Soils. Journal of Biology and Fertility Soils, 18, 311-319. http://dx.doi.org/10.1007/BF00570634

[20] Mergeay, M., Monchy, S., Vallaeys, T., Auquier, V., Benotmane, A., Bertin, P., Taghavi, S., Dunn, J., Van der Lelie, D. and Wattiez, R. (2003) Ralstonia metallidurans, a Bacterium Specially Adapted to Toxic Metals: Toward a Catalogue of Metal-Responsive Genes. FEMS Microbiology Reviews, 27, 385-410. http://dx.doi.org/10.1016/S0168-6445(03)00045-7

[21] Kermasha, S., Pellerin, F., Rovel, B., Goetghebeur, M. and Metche, M. (1993) Purification and Characterization of Copper-Metallothioneins from Aspergillus niger. Bioscience, Biotechnology and Biochemistry, 57, 1420-1423. http://dx.doi.org/10.1271/bbb.57.1420 